developed countries, as it is pointed out, must be considered as ancillary to all the instruments available for the control of tuberculosis. These have been listed in a recent review by an eminent professor and expert in tuberculosis, J. W. Crofton, as BCG and the general improvement in the standard of living to raise community resistance, miniature radiography, chemotherapy, appropriate isolation, improved ventilation and the reduction of overcrowding in home, work, play and transport.

Reference is also made to control of bovine tuberculosis; with regard to this it is appropriate to mention the recent announcement by the Ministry of Agriculture that October 1, 1960, marked the end of a concentrated effort to reduce the incidence of bovine tuberculosis in Britain to a degree that it is no longer a national problem in that it has been virtually eradicated by attestation of the herds of the whole country. It is stressed that the present position with regard to human tuberculosis does not justify complacency. However, it is considered that a stage has been reached when it is possible to see how the main weapons against tuberculosis can be applied, and that provided there is enthusiasm and public backing to the end, there is a prospect of foreseeing the elimination of tuberculosis in the not too distant future. The problem in the undeveloped countries is more difficult. It is commented that BCG has an important part to play in economically developed countries, and it might be even more useful in the others provided that the efficacy and appropriate use of the vaccine is kept under constant review in the laboratory and in the field.

In this connexion it is interesting that what is considered as one of the most convincing studies of the protective power of BCG vaccination was first reported by Aronson in 1948. North American Indian children and young adults who did not react to tuberculin were divided into groups of 1,550 vaccinated with $B C G$ and 1,457 unvaccinated. There was segregation of the first group for two months after vaccination. Tuberculin testing and radiographic examination was carried out each year for seven years and at the end of this period 4-5 times more unvaccinated had developed tuberculosis than the vaccinated and the mortality-rate from tuberculosis was seven times higher in the unvaccinated. It is interesting to note, in view of the early demonstration by Calmette and Guérin of the immunizing value of BCG in cattle, that it is now considered that control of tuberculosis should, whenever possible, be by an eradication scheme based on attestation of herds by tuberculin testing. Since BCG vaccinates are sensitized to tuberculin, diagnostic procedures are difficult and thus BCG can play no part in such a scheme. Nevertheless, although the BCG vaccine has become established as safe and effective, it had a very stormy history and one of the roughest passages of any vaccine before final acceptance. Undoubtedly, one of the major setbacks was the unfortunate incident in 1930 in Lubeck in Germany when 78 out of 251 infants believed to have been vaccinated with BCG, but who as was later established by official inquiry had been inoculated in error with fully virulent human culture of the tuberculosis bacillus, died. Until the result of the official inquiry had confirmed that BCG was not responsible, Calmette and Guérin suffered adverse criticism and vituperation from all quarters, including that from those who had warned that reversion to virulence was possible and here was the proof.
Although BCG was exonerated, the incident had unfortunate repercussions, and it was a very long time before confidence in the safety and efficiency of the vaccine was established. Calmette especially was greatly shaken by the incident. He did not have the resilence of Pasteur in dealing with his detractors. The worry, strain and the vilification by the critics together were too much for him. He died in 1933, a disappointed man broken in spirit and health.

Guerin continued the fight against tuberculosis as chief of the BCG service in the Pasteur Institute for another ten years, consolidating the victory, opposing the doubts and eritics with his lucid, well-considered judgments. Even after his retirement, he gave encouragement and advice to those who took over from him. Guérin was a member and president or vice-president of many learned societies and, in addition to receiving many foreign decorations, his contribution to the control of tuberculosis was recog. nized with gratitude in 1952 by the award of the Grande Médaille de Vermeil de la Ville de Paris, in 1955 by a prize of one million francs by the Academy of Sciences and appointment as Grand Officier de la Légion d'Honneur in 1958.

Those who knew Guérin recognized his charming modesty and great affability, and what gave him the greatest satisfaction was presiding at the First International Congress of BCG in 1948 and the opportunity of surviving long enough to witness the ultimate success of $B C G$, the universal recognition of the safety and efficacy of the vaccine which he and Calmette had struggled to develop nearly half a century ago.

Ian A. Galloway

\section{Prof. R. M. Gordon, O.B.E.}

Rupert Montgomery Gondon, professor emeritus of parasitology and entomology in the School of Tropical Medicine, University of Liverpool, died on July 26, 1961, aged sixty-seven. During his youth he lived in Phoenix Park, Dublin, and there he developed early an interest in biology. He graduated in medicine in Trinity College, Dublin, in 1916, and, joining the Royal Army Medical Corps, he spent the war years in the Middle East. He was demobilized in 1919 and joined the staff of the Liverpool School of Tropical Medicine. He was soon sent to work for some two years in the School's laboratory at Manaos in Brazil, and on his return he became house physician and clinical pathologist to the Tropical Ward in Liverpool. In 1924 he was transferred to the Sir Alfred Lewis Jones Research Laboratory in Sierra Leone, where he became director in 1929 and professor of tropical diseases of Africa. In 1937 he returned to Liverpool to the chair of entomology, and in 1941 he became the first occupant of the Dutton and Waltor Myers chair of entomology and parasitology.

$\mathrm{He}$ was president of the Royal Society of Tropical Medicine and Hygiene during 1955-57, and he was awarded the Chalmers Memorial Gold Medal in 1937. On his retirement he received the Mary Kingsley Medal of the Liverpool School of Tropical Medicine. He was an active member of many scientific committees and an editor of the Annals of Tropical Medicine and Parasitology for 28 years. In collaboration with Dr. M. M. J. Lavoipierre he completed a text-book on medical entomology shortly before his death.

Prof. Gordon was author of more than one hundred scientific papers which covered a wide range of subjects. In addition to many minor studies he made 
major contributions to medical parasitology in connexion with the epidemiology of malaria; the vectors of schistosomiasis and the development of the worms in the final host; metazoan immunity; the reaction of the human host to the bites of insects; the epidemiology of filariasis, especially loaiasis; and the doposition and development of trypanosomes deposited in the mammalian host by tsetse flies. One of his most notable achievements was his investigation of the behaviour of the mouthparts of bloodsucking arthropods during the act of feeding. He and his colleagues devised a method by which the mouthparts could be photographed on cine colour film in the host's tissues while feeding, and several cine films were made.

As a man, Prof. Gordon earned the affection of his junior staff and colleagues. He was deeply loyal to the School and to his friends, and he took a personal interest in encouraging the development of his young research workers. He was a tireless worker, a very fine teacher and an amusing companion. His wide experience and broad vision enabled him to throw fresh light on any problem he investigated, and his stimulating approach and constructive criticism will be sadly missed by workers in the field of medical parasitology.
T. H. DaveY

\section{NEWS and VIEWS}

\section{Fluid Mechanics at Glasgow :}

Prof. T. R. F. Nonweiler

Dr. Terence Nonweiler has been appointed to the Mechan chair of aeronautics and fluid mechanics at the University of Glasgow in succession to the late Prof. W. J. Duncan. For the past four years Dr. Nonweiler has been a senior lecturer in aeronautical engineering at the Queen's University of Belfast, having previously held the same office at the College of Aeronautics. For some years he has acted as consultant to the Admiralty. $\mathrm{He}$ is an Associate Fellow of the Royal Aeronautical Society and also of the Institute of Aero Space Sciences and a Fellow of the British Interplanetary Society. Dr. Nonweiler is well known for his many contributions to theoretical aerodynamics, to space technology and to the problem of the stability of submarines. In addition, he has been a moving spirit in the recent campaign for the achievement of man-powered flight.

The appointment of Dr. Nonweiler to a chair with responsibilities for the education of both aeronautical and mechanical engineers is particularly felicitous in that his. interests and experience cover the whole range of fluid mechanics. Moreover, several fields in which he has long been interested are likely to become increasingly prominent in the immediate future.

\section{Progress on the Advanced Gas-cooled Reactor at Windscale}

THE 135-ft. diameter containment building which encloses the advanced gas-cooled reactor, now nearing completion at the Windscale Factory of the Atomic Energy Authority, Cumberland, was successfully tested over the August Bank Holiday week-end. The holiday period was chosen so as to cause minimum interference with other work on the site and with the Factory. Very satisfactory results were obtained from sub-atmospheric strength and leak tests. The pneumatic strength test at $12.5 \mathrm{lb} / \mathrm{sq}$. in. (gauge) necessitated the diversion of traffic from the adjacent public road as a precautionary measure. The advanced gas-cooled reactor represents the next phase of development of the graphite-moderated gas-cooled reactor beyond the basic Calder Hall design adopted for the first round of British nuclear power stations now being built. The main objective of the reactor is to reduce the capital cost of reactor installation, and this will be done by raising the steam temperature and increasing thereby the amount of heat generated from a given size of reactor. Higher temperatures will be made possible by the use of uranium oxide fuel, which will be put into the reactor in stainless steel and beryllium 'cans'.

\section{Industrial Water and Effluents Group}

A NEW group of the Society of Chemical Industry, to be known as the Industrial Water and Effluents Group has been formed under the chairmanship of Dr. B. A. Southgate, director of the Water Pollution Research Laboratory of the Department of Scientific and Industrial Research. The new Group will be concerned with the broad subject of industrial water, from supply, through treatment and use, to ultimate disposal. Among the subjects which will receive special attention by the Group are: availability of water for the future needs of industry; quality requirements for water for industrial use; treatment of water for process, steam raising and cooling purposes; conservation and re-use of industrial water; methods of treatment and disposal of water-borne wastes; industrial location and development, as governed by water supply and waste water disposal facilities; effects of industrial effluents on natural waters. The first meeting of the Group will take place at the Royal Institution, Albemarle Street, London, W.1, on November 1. Applications for membership and further information can be obtained from the General Secretary, Society of Chemical Industry, 14 Belgrave Square, London, S.W.1.

\section{Atomic Research and International Co-operation}

A REPORT, New Trends in Atomic Research and their International Significance, prepared by Dr. L. Kowarski, scientific adviser to the European Nuclear Energy Agency, and submitted to the Agency's Steering Committee, surveys the scope for international action in nuclear research and the opportunities of co-operation and makes several suggestions for such action (Pp. 36. Paris: Organization for European Economic Co-operation, European Nuclear Energy Agency, 1961). These are to be examined by a meeting of experts from member and associated member countries which is expected to take place during October. Dr. Kowarski assumes that fundamental research in this field is likely to be carried out in a clearly autonomous division of a large centre or in a separate centre, and that the need for largescale planning, especially in semi-applied research, will encourage international co-operation. He believes 